\title{
Devising Effective Strategies and Policies for CSA: Insights from a Panel of Global Policy Experts
}

\author{
Patrick Caron, Mahendra Dev, Willis Oluoch-Kosura, Cao Duc Phat, \\ Uma Lele, Pedro Sanchez, and Lindiwe Majele Sibanda
}

\begin{abstract}
In this section, we present the results of a consultation with a panel of leading thinkers on agricultural and climate change policy. We interviewed these experts using a set of questions based on the main findings, conclusions, insights and questions that emerged from our set of case studies and conceptual papers. This section is divided into four parts, each focusing on a set of questions relating to the conclusions that emerged from the case study and conceptual chapters. (i) Focus on changes in production systems as adaptation: priorities and policy actions; (ii) Incorporating climate change into agricultural research and extension; (iii) Taking a close look at national policies affecting risk management: index insurance, safety nets and input subsidies and (iv) Priorities for the future and summary of main points. Overall, there is a fairly high level of agreement amongst the panel members in responding to most of the interview questions, although with some difference in emphasis or applications. However there are also some differences of opinion that emerge from their responses. In this chapter, we discuss the main points made on each of the issues addressed, highlighting the areas of agreement, as well as differences.
\end{abstract}

P. Caron $(\square)$

CIRAD, Montpellier, France

e-mail: patrick.caron@cirad.fr

M. Dev

Centre for Economic and Social Studies, Hyderabad, India

W. Oluoch-Kosura

University of Nairobi, Nairobi, Kenya

C.D. Phat

Agriculture and Rural Development, Hanoi, Vietnam

U. Lele

World Bank, Washington, DC, USA

P. Sanchez

Earth Institute, Columbia University, New York, NY, USA

L.M. Sibanda

Food, Agriculture and Natural Resource Policy Network, Pretoria, South Africa

(C) FAO 2018

L. Lipper et al. (eds.), Climate Smart Agriculture, Natural Resource

Management and Policy 52, DOI 10.1007/978-3-319-61194-5_24 
About panel of leading thinkers on agricultural and climate change policy

Patrick Caron, CIRAD Chair of the High Level Panel of Experts/HLPE of the committee on world food security (CFS).

Mahendra Dev, Director, Centre for Economic and Social Studies, Hyderabad India

Willis Oluoch-Kosura, Professor of Agricultural Economics, University of Nairobi

Cao Duc Phat, Minister of Agriculture and Rural Development Socialist Republic of Vietnam

Uma Lele, Kamesh Deshpande and Inder Abrol, Uma Lele is an independent researcher, and former senior advisor in the World Bank. Ramesh Deshpande is former Principal Financial Operations Specialist of the World Bank, presently CEO at IAG International. Inder Abrol, is former Deputy Director General of ICAR and former Facilitator of the Rice-Wheat Consortium.

Pedro Sanchez, Director of the Agriculture and Food Security Center and Senior Research Scholar at Columbia University's Earth Institute

Lindiwe Majele Sibanda, Chief Executive Officer and Head of Mission Food, Agriculture and Natural Resource Policy Network

\section{Focus on Changes in Production Systems as Adaptation: Priorities and Policy Actions}

Several of the case studies presented in the book give indications of changes in agricultural practice management that are effective adaptation actions. These include a wide range of practices that fall under the general categories of sustainable land and water management (SLWM), as well as diversification of farming systems and livelihoods. These practices are already known and available, and yet adoption rates are generally not very high. As shown in the case studies there are considerable barriers to their adoption, such as increased labor/capital inputs as compared to 'conventional' technologies, or up-front costs of investing in soil health and farm structures, which may take several years to bear fruit. The case studies also indicate that farmers located in areas facing greater climate risks are more likely to diversify agricultural production, labor and incomes, which decrease their vulnerability to extreme weather events. However, as with adoption of SLWM practices, evidence suggests that it is often the wealthiest and more educated farmers who are able to 
take advantage of opportunities to diversify. The case studies presented, as well as more general literature on adaptation, indicate that water management is a key issue for climate change adaptation and increasing resilience in agriculture. It can be a successful - and essential - adaptation strategy but it requires substantial public investments, which can be problematic when resources are scarce. Managing irrigation schemes after the initial investment can also lead to smaller gains than originally anticipated.

We asked our panel to respond to three questions related to these findings:

(i) How important do you think it is for policy-makers to promote SLWM practices and what role does policy play in promoting it?

Cao Duc Phat considers SLWM important to address climate change and improve the sustainability of natural resource use. This is particularly important in densely populated rural areas as in Vietnam, where land pressures are rising due to urbanization and industrialization, further exacerbated by sea level rise. SLWM allows for sustainable intensification of production systems, and thus is essential to ensure livelihoods and stable living conditions for rural residents.

Public-private-partnerships (PPP) are an important means of promoting adoption of such techniques. The public sector can invest in infrastructure and enhance private sector investments with improved access to credit and insurance. It also has an important role to play in developing flexible land use policies that are needed to enable widespread adoption. Sanchez sees the development of an enabling value chain as essential for promoting SLWM across the entire value chain, from services to production, to value added, transport, market, consumption and consideration of environmental effects. He states:

I think what is really needed is to bundle many of these services in a way that provides good tools to farmers so they don't have to worry about things like credit or where to sell their crops.

He also raises the role of private sector in this effort, citing the example of farmers in Kenya that are contracted to private sector companies where they obtain inputs, fertilizers, improved varieties, credit, crop insurance, and market. This leaves farmers to focus on farming. Sanchez notes that better leadership and outreach activities that establish sustainable social norms are important. The Millennium Villages provide examples of how leadership has helped spread SLWM practices among all strata of farmers.

Lele and colleagues give considerable weight to the need for better soil management - particularly improved nutrient management. They consider case of conservation agriculture (CA) as an important part of the solution in India. However there are major constraints to its adoption amongst smallholder farmers: (i) competing use of crop residues in rain fed areas, (ii) weed management strategies, particularly for perennial species, (iii) localized insect and disease infestation, and (iv) likelihood of lower crop productivity if site-specific complementary technologies are not adopted. 
They argue that:

For wider adoption of CA, there is an urgent need for policy makers, researchers and farmers to change their mindset and explore these opportunities in a site- and situation-specific manner for local adaptation.

A policy framework that recognizes the value (or costs) associated with externalities is important according to Sanchez and Caron. Sanchez argues that positive externalities like soil carbon, improved ecosystems for wildlife, and increase food security (by enhancing resilience) and therefore agriculture should be compensated. Caron also emphasized the need for policies to provide incentives to engage in activities that provide social goods and reduce negative externalities which are particularly important in the SLWM context.

Sibanda states that investment in SLWM is a "must-do" - noting that it is the first pillar for the Comprehensive African Agriculture Development Program (CAADP) because its importance was well recognized. However it hasn't been fully implemented - due to limited funding, but also institutional issues such as land tenure systems.

Because we're focusing on smallholder farmers, you are dealing with land that is communally owned: they are not titled to land, you are dealing with farmers that are sitting on 1 hectare but relying on public irrigation facilities; you are dealing with farmers who are relying on lands which is not clearly demarcated as owned by the individuals. Now, how likely is it a farmer will pour money into such a situation?

She argues that the solution is to revisit the issue of land tenure to build incentives from the bottom-up so farmers who are willing to invest will be guaranteed that they, their children and grandchildren will have use of the land. They will also be able to use the title to borrow money - an important aspect Cao Duc Phat raises in the Vietnamese context as well.

Kosura sums it up as follows:

Promoting secure land tenure regimes especially by governments is a key prerequisite for investment in SLWM.

(ii) What types of public investments or policy options do you believe would improve poor farmers' ability to diversify?

Caron stressed that it is important to realize that even the wealthier and educated farmers in the areas considered by the case studies are relatively poor, and poor farming households are generally fairly diversified. Dev concurs adding that in India small farmers allocate a larger proportion of their cultivated land to high-value crops like fruits and vegetables. The issue is not so much to promote diversification amongst the poorest, but to build mechanisms to help them take advantage of opportunities. Dev notes that a number of innovative institutional models are emerging to help support opportunities for small and marginal farmers in India. These include institutions relating to (a) land and water management, (b) group or cooperative approach for inputs and marketing and, (c) value chains and supermarkets that can enhance productivity, sustainability and incomes of small holding agriculture. 
According to Kosura, public investments in infrastructure (rural roads, market places, storage facilities) and related services are needed to reduce transactions costs faced by the poor - which private and public sector partnerships can foster. Sibanda focuses on the public sector role in building market infrastructure, as well as public investments in land and water management that reduce impacts of extreme events to compliment farmers' own actions. She also thinks that it is important to consider the results of climate models and to the foreseen impacts of climate change in deciding policy priorities for diversification. For example, areas traditionally known for being bread baskets may become food hunger spots, and may therefore need to rely on food imports. There needs to be an update of the mapping of whoproduces-what with important implications in terms of crop diversification. Trade therefore plays an important role in facilitating this process.

Dev lays out four key areas of institutional support needed to support diversification for smallholders: (1) enabling farmers' groups and cooperatives to help smallholders access high-value markets through, for instance, improved rural - urban linkages; (2) a wider range of viable and attractive financial and risk management tools; (3) increasing information dissemination needed for smallholders to increase knowledge and technical skills to take advantage of diversification strategies, and (4) ensuring livelihoods are protected in the aftermath of severe weather events through social safety net programs.

Cao Duc Phat broadened the discussion on diversification to consider the importance of creating more employment opportunities in rural areas, including nonagriculture based opportunities, as an essential component of diversification. Specific technical guidance, production support programs, and state-targeted support in terms of capital and extension services are needed to enable farmers, particularly the less wealthy, to take advantage of a wider range of economic opportunities. He also stresses the need for both the public and private sector involvement in expanding access to non-farm income opportunities in rural areas.

Dev and Kosura also take up the issue of the role of trade in adaptation, and it implications for diversification. They point out that climate change effects are varied across locations, and thus opens a possibility of exploiting new comparative advantages in trading. Changes in both domestic and foreign trade may be appropriate, with regions or provinces shifting production patterns in response to the types of risks they face. However Dev also points out that trade can impose risks, through market volatility, and this is an important aspect for policy to address, in order for trade to support increased food security under climate change.

(iii) What priority should be given to irrigation expansion as an adaptation strategy?

Dev points out that irrigation expansion is the most important priority as it protects farmers and other people from climate risks. Sibanda says that Africa cannot continue depending on rainfed agriculture, as it is not a climate-smart strategy, it does not build resilience, and does not contribute to lower risk. Kosura argues that irrigation is critical considering the erratic nature of rainfall in recent years. Irrigation not only alleviates water stress but also has the potential to expand the opportunities 
for switching planting dates and crop varieties, as well as increasing returns on investments in fertilizer and other inputs. Caron thinks that irrigation is key for production but with different roles in different areas. Where irrigation has already expanded, there are issues of sustainability and competition with alternative uses (industrial and urban). On the contrary, in other areas - for example in low density areas where agriculture has been expanded through an extensive process rather than through intensification - irrigation may not have been used as a way to increase production because of investment barriers. Dev says that in many countries it may be necessary to develop big irrigation projects as micro-irrigation may not be enough, but replacement and rehabilitation mechanisms have to be in place when large scale irrigation is developed. In other contexts, there may be the need to develop micro-irrigation projects which better suit local conditions and capabilities. For example, watershed development (e.g. small check dams) can particularly help small farmers.

Kosura would support low-cost small irrigation systems through financing and technical assistance. He thinks that there is much scope for expansion through micro projects, which require local management capabilities, and improved management of existing irrigation schemes. Research by agencies like International Water Management Institute (IWMI) has revealed a growing trend for individual and community-owned agricultural water management systems. Encouraging a cooperative farming approach (collective action) to irrigation would reduce costs and allow greater benefits to the farmers. Sanchez agrees with this line of thinking, arguing that for developing countries it is better to have small scale irrigation where people owning the systems (e.g. Farmers' Associations) are more likely to efficiently manage the resource. Sibanda mentions that Africa is still bearing the cost of establishing big irrigation schemes which show below-average rate of investment returns and high maintenance costs. It is not surprising therefore that the extension of irrigated land in Africa is very limited. Policies should promote technologies that will lower the cost of establishing irrigation infrastructure and its maintenance. In order to have an irrigation scheme commercially operational and to improve returns for the farmers, three issues should be considered: governance arrangements (water access, infrastructure management, property rights); institutions (extension services, water management committees); markets (farmers accessing irrigation should grow high value crops and have access to market economy).

The priority for Sanchez is the so called "green water" associated with soil moisture that represents $2 / 3$ of the water used by agriculture. The priority is to use this more efficiently - which means getting improved production practices in place. He provides the example of rainfed maize production in Malawi to illustrate the concept. At the current levels of about 1 metric ton per hectare, about $80 \%$ of the water is lost to evaporation, while the other $20 \%$ or so is transpired through the plant making biomass that is harvested. If you tripled that yield, you could get about $80 \%$ of that soil moisture going to transpiration and losing only $20 \%$ to evaporation. Why? Because a crop cover holds down evaporation; and then the roots of these plants that are fertilized, can reach water at greater depths so that soil moisture is the source of green water, which is to Sanchez the most important. 
Cao Duc Phat lays out the current thinking on irrigation investment and adaptation in Vietnam:

After a period focusing on building large scheme irrigation infrastructure serving for production development, there is now increased interest in building irrigation works that serve for adaptation to climate change with new priorities: enhance local needs, adjust irrigation management appropriately to transform the production practices, protect landscape, conserve water resources and take the most effective use of designed facilities' capacity; reform the operational mechanism, better utilize existing infrastructure systems and improve water use and management efficiency; consider multiple water uses and promote water-saving practices; implement PES schemes to share part of the water users' profits with forest planters and protectors to regenerate water resource in the watershed upstream; invest in critical disaster prevention infrastructures (e.g. flood control and drainage); strengthen management of small and medium irrigation infrastructures throughout capacity building for the local officials and people.

Institutions are key in proper water management and for improving efficiency in adaptation. Dev says that mere increases in water pricing may not result in financial sustainability unless institutions are in place to recover water charges. Reforming institutional structures in favor of Participatory Irrigation Management (PIM) and Water User Associations (WUA) have to be strengthened, together with the promotion of participatory monitoring and evaluation. Dev also thinks that the development of groundwater markets would take care of the equity problems to a large extent. But the evolution of water markets is possible only in those regions where groundwater is available in sufficient quantities. Also, profitability of groundwater exploitation should be raised and users should be involved in the management of irrigation systems.

Most experts agree that a big role in promoting the sustainable use of water for adaptation can be played by technology innovation. Sanchez thinks that, regardless of how that water gets to the field, shifting from furrow irrigation and gravity flows, into sprinklers or drip irrigation, irrigation water can be used a lot more efficiently and in a climate-friendly way. Lele and Dev agree that drip irrigation, which is often described as a water "saving" technology, can be of great help in saving resources and increasing water productivity. However, Lele also warns that technologies that seem water conserving, like drip irrigation, can actually increase overall demand for water:

Investments in irrigation expansion for years have not increased the amount of irrigated areas, nor improved timely reliable supply of water for agriculture over decades (Lele 2013; Lele et al 2013). The result is overexploitation of groundwater and it has been hard to tame the groundwater anarchy. ${ }^{1}$ Recent technological development has been the growth of drip irrigation which is often described as water "saving". However recent evidence suggests that drip irrigation is likely to increase rather than save water for at least two reasons. First, increase in crop productivity has an almost a one to one relationship with transpiration (Steduto et al), and increased profitability of investment in drip irrigation is already leading to the rapid spread of drip irrigation through the so-called "Jevon's effect".

\footnotetext{
${ }^{1}$ Shah, T. (2009). Taming the anarchy groundwater governance in South Asia. Washington, DC: Resources for the Future. http://site.ebrary.com/id/10570436.
} 


\section{Incorporating Climate Change into Agricultural Research and Extension}

A second major finding that emerged from the case studies is the need for explicitly incorporating climate change effects into agricultural research and extension activities. The case study findings suggest that (i) managing more integrated and accessible climate and agriculture data at different levels, (ii) expanding research to identify farming practices adapted to the specific climate and farming characteristics (e.g. crop variety breeding programs; farm practices adapted to labor constraints; soil and water management investments adapted to local agro-ecological conditions) and (iii) supporting informed, and continually updated, training and extension programs can increase resilience and food security of agricultural households.

We asked our policy experts their views on these activities.

\subsection{Climate Data}

Starting with the discussion on climate data and its accessibility, there was unanimous agreement that enhancing access to climate data for agricultural producers (including farmers, fishers, foresters and livestock keepers) is quite important and should be given higher priority. However there were differences in which aspects of access should be emphasized, from improving production of the data, to better integration with agricultural data and better delivery of the data, and finally to improving the capacity of the farmers to actually use the data.

Dev points out that currently there is a disconnect between climate and agriculture data, with little integration between the two - including from local to global scale. Technologies such as satellite and remote sensing can play an important role in generating integrated data - but cooperation at global and regional levels will be needed to achieve this.

Delivering and transferring the information is as important as generating it. Caron notes that enhancing the current means that farmers get information, for example through the provision of additional information delivered through cell phones, is an important means of increasing access. Cao Duc Phat raises the importance of reaching remote and isolated farming communities that are highly vulnerable to climate risks, and which currently do not have good access to climate information. In stressing the importance of climate information delivery systems, Lele and colleagues provide the example of India's Meteorological Department (IMD) which has developed a framework for reaching climate information to farmers and fisher people through the use of cell phones. A key element of the IMD program is the Agro-meteorological Advisory Service (AAS), which customizes climate information relevant to the district in which it operates. Despite the benefits this program has generated in terms of reducing losses (including of lives), it is 
severely hampered by low percentage of cell phone ownership amongst farmers as well as limited awareness of the availability of climate information and inadequate technical capacity at the AAS district level to generate local level forecasts. Lack of human capacity in institutions at local level is also highlighted as a key issue by Sibanda and Kosura.

The lack of capacity of farmers (or any type of agricultural producer) to utilize climate information and thus the need for education at the farm level was raised by several of the policy experts. Sanchez notes that the more smallholders know about the dangers of climate change the better, and education as well as joint actions between climate and agricultural technical agencies is needed. Lele and colleagues point out the need for enhancing capacity amongst women in particular, as they play decision-making roles in ensuring household food security.

Sibanda reports on the results of a study done by FANRPAN in 2015 in 15 countries that indicated lack of human capacity as a key limiting factor. Not only the capacity of farmers to access knowledge and absorb it, but also the capacity of institutions that lack facilities as well as knowledge to cope with these new and complex issues. Pedro Sanchez argues that we need education not only for farmers, but for the general public which influences policies.

\subsection{Farming Systems Research}

All the policy experts felt that farming systems research with integration of adaptation merits greater priority. Cao Duc Phat, Sibanda and Dev emphasized the importance (and difficulty) of shifting away from research and technical assistance focused on single commodities, to a more integrated and systems based approach to analyzing farming systems.

Lele et al. argue that rapidly changing conditions facing agriculture require system thinking including both farm and non-farm aspects. They write:

There is a growing recognition among developing countries' public sector research institutions that given the changed environment in which agricultural sector now works, coping with challenges such as reduced availability of quality water, nutrient deficiency in soils, climate change, farm energy availability, loss of biodiversity, emergence of new pest and diseases, fragmentation of farms, rural-urban migration, coupled with new IPRs and trade regulations, agricultural research programs must undergo a paradigm shift fully harnessing the potential of modern science, encourage innovations in technology generation, and provide an enabling policy and investment support. And in this research, priority must be given to some of the critical areas such as genomics, molecular breeding, diagnostics and vaccines, nanotechnology, secondary agriculture, farm mechanization, energy and technology dissemination. ${ }^{2}$

Caron makes the point that we already have a tremendous amount of information to support better farming systems research but we need better coordination to

${ }^{2}$ Vision 2050 document of ICAR's Indian Institute of Farming Systems Research (IIFSR), Meerut, UP, India. http://www.icar.org.in/Vision\%202050\%20IIFSR,\%20Meerut.pdf. 
effectively access it. Kosura cites the difficulties of building good and representative typologies of farming systems, considering the huge variability in biodiversity, scales, management systems, cultural diversity and resource base - although these may be overcome by more targeted investment and training. Lele also raises the problem of several different, and in some cases contradictory, approaches that involve or invoke farming systems research, including Climate Smart Agriculture, sustainable agricultural intensification, Conservation Agriculture and others. She calls for a common understanding and definition of sustainable intensification as an important means of improving the effectiveness of farming systems approaches. Caron argues that FSR should not only be a means of looking at what is out in the field today - but also a means of reflecting on possible options for moving forward.

\title{
2.3 Extension
}

On the discussion on extension, Lele et al. point out that the term "Extension" which signified a top-down, uni-directional approach to technology transfer has long been replaced by "Agricultural knowledge information systems" (AKIS) and later by Agricultural Advisory Services. All of the experts agreed that it is absolutely essential to move away from top-down systems to ones where knowledge flows in multiple directions.

Caron argues for new institutional approaches to extension based on the challenges it is now facing. He says:

\begin{abstract}
In the past, the agriculture revolution has been based on major disruptive innovations, such as genetics, mechanization or chemical inputs. We know that the future transition or the future revolution of agriculture will have to take stock of many, many different types of innovation and that it will be knowledge and information intensive. It will be important to bring disruptive innovation and technologies together with farmers' know-how to be in a position of making the best choice out of that. Of course extension is the way through which all this information can be used and can be put into practice. It means that extension needs institutional arrangements that allow for information exchanges amongst stakeholders.
\end{abstract}

Lele et al. put the role of extension in historical perspective. Since the Green Revolution there has been tension between commodity-oriented extension and extension oriented towards farming systems. In part that is also related to the changing roles of the public and the private sectors. Studies in India show that only $6.5 \%$ of the information farmers get is from public extension, $20 \%$ is from farmer to farmer contacts and 20-29\% from newspapers, radios and TV. As research and input delivery has moved into private hands and inputs and market access have become important in a diversified agricultural production system, private dealers have become an important source of information for farmers on niche commodities, livestock, poultry, fruits, vegetables and edible oils, and new private sector extension systems have emerged as part of the growing value chains. Through experience and contract farming the emerging input providers are learning to provide integrated 
services to farmers, albeit with many hitches on the way. They conclude by calling for a redefinition of the public extension system:

The role of public extension system, and of governments in technology transfer, now needs a clear redefinition, which many extension systems currently lack. With the growing emphasis on sustainable agriculture, that emphasis should be on natural resource management in the overall farming systems, including in water, soils, agro-forestry and the mother of them all, climate change. Traditional extension systems, by and large, used technical staff that were specialized in a particular branch of agricultural science such as agronomy, plant pathology, soil science, plant breeding, animal husbandry, fishery, without necessarily having a comprehensive understanding of agriculture using a farming systems approach. Being supply-driven, the public sector extension services have proved to be ineffective in terms of disseminating information to a whole farm management in a timely manner, going beyond farmer needs or expectations to manage externalities that spill over small fields and farms.

\section{Sibanda also calls for a redefinition of extension in the African context:}

Yes, our extension services need greater strengthening but let's revisit the drawing board in terms of what type of extension service is required to deal with the multi-sectorial, multicausal problems'. You are no longer dealing with an agent who knows everything, you need an extension agent who learns from the farmers, who promotes learning; you are dealing with an agent who will be able to bring information outside agriculture in a way that can be absorbed and understood by farmers; you are also dealing with an advisory system whereby we promote farmer-to-farmer learning; all this is different from the way the old policy for extension services was designed, i.e. top-down. We now need a bottom-up, cross-learning and inter-sectoral learning.

Both Kosura and Dev emphasize the need for building proper incentives into extension systems to promote higher quality services and better interactions and exchanges with farmers. Kosura gives some concrete examples of how this could be done, including making funding conditional upon the development of effective links between researchers and farmers through adaptive research and extension programs, the use of innovative approaches such as vouchers for advisory services, which could be given to farmer groups to source extension services from private sector providers, and the use of ICT for information and advisory services.

The lack of political will is perhaps the most important constraint to achieving more effective research and extension system, an issue that raised by almost all the experts. Pedro Sanchez provides a different and more optimistic view of the possibility of garnering political will at this time. He notes:

Right now we are at a very, very positive point in this whole struggle, because (i) the MDGs have finished last year and they have been eminently successful, (ii) there is a new set of sustainable development goals (SDGs) which are better, more sophisticated to keep the world together, and (iii) the Paris Agreement on climate change. All came about at the same time, on the same year, and it gives a tremendous opportunity to really link agriculture and climate change.

Even if the political will to take action on agriculture and climate change in an integrated fashion is indeed increasing, tackling the problem requires policy coordination with multiple sectors beyond these two. Cao Duc Phat comments: 
There is a lack of consistency between sustainable agricultural development activities and general development orientation and with other sectors (infrastructure, science and technology, urban development, development of non-agricultural economic industries).

Sibanda also raised the issue of coordination with sectors outside of climate change and agriculture, because the problem is multi-causal and the solutions multi-sectoral.

Even within the more circumscribed context of coordination across climate change and agriculture, there are significant barriers. In the Indian context, Lele et al. note that the lack of convergence among different agencies - local, regional or national - dealing with climate change and agriculture is a major problem. The absence of effective convergence involves huge administrative overheads, reduced outlays on real sector development, and absence of a cohesive approach to climate change mitigation and adaptation.

\section{Taking a Close Look at National Policies Affecting Risk Management: Index Insurance, Safety Nets and Input Subsidies}

Index insurance, safety net programs and input subsidy policies are all development policies that have effects on risk management, which is an important facet of adaptation, although they are not designed with adaptation explicitly in mind. The case studies in the book indicate these policies can have both positive and negative effects on adaptation. They may also not be very effective under changing climate as well as broader development conditions.

Index insurance has been hailed as an important tool for increasing resilience in smallholder agriculture livelihoods - but the case study findings indicate that subsidies are essential for the program to be operational (in absence of subsidies the program is too expensive for the farmer). Extending any type of insurance to individuals in remote locations will likely be of extreme difficulty, even subsidized products.

In the last decade, there has been an expansion of safety-net programs in African countries with the aim of reducing poverty and increasing food security: in most cases targeting focused on economic vulnerability rather than climate vulnerability. However, the case study findings indication that a cash transfer program is effective in managing climate risk and potentially mitigating the effects of climate change.

Input subsidy programs have been promoted against the background of bad weather affecting production and with an aim of increasing resource-poor smallholder farmers' access to improved agricultural inputs. However, programs have not been fully exploited to address constraints associated with climate risk. It is also often criticized for poor targeting at the farmer level. 
We asked our panel to comment on each of these policies in terms of their potential role in adaptation, and the types of adjustments that may be needed to realize their effectiveness.

\subsection{Index Insurance}

Index insurance is an important tool for managing climate risk according to Sanchez, but certainly at the very beginning, for all these interventions, they need for some type of subsidy to be successful. Sibanda takes this further citing the cases of subsidized weather-based index insurance in Uganda, Zambia and Swaziland conducted by FANRPAN last year. The results of that study indicate the potential for weather based insurance, but also some key factors to ensure its success, including the importance of organizing farmers into groups. Subsidizing the insurance is an important way of getting people into a new way of doing things. It is key to build the human capacity needed for effective management of such schemes: by training local insurers on the businesses of insurance in agriculture and at the same time helping people to understand what it means to keep records, subscribe as a group, and work through group ownership. She says:

What is exciting is that through insurance you're now creating a business of a bankable industry whereby you're introducing services that would actually escalate beyond primary entry point which is agriculture.

Dev notes that although crop insurance schemes have not worked in many parts of the world, in recent years these schemes are becoming more effective. In the past, measurement of losses was costlier and he argues that weather index-based insurance can make it cost effective for farmers. Recently, India introduced a new crop insurance called Pradhan Mantri Fasal Bhima Yojana (PMFBY) (Prime Minister's Crop Insurance Scheme). In the previous schemes, premiums were high and coverage in terms of sum insured (SI) was inadequate. The new scheme corrects these two problems. It also broadens the definition of risk to include yield losses, preventive sowing, and post-harvest losses. Farmers now have to pay a uniform premium depending on the types of crops. The gap between the actual premiums and the rates payable by farmers would be fully met by the government. He points out:

The new crop insurance can be a game changer if the conditions of low premiums and the SI covering the gross value of output are met along with quick claim settlements with mobile and satellite technology.

For Kosura building capacity in the insurance sector as well as amongst farmers is important and thus he advises:

Insurance programs face barriers since providers are still reluctant to deal with agriculture. Working with insurers to understand the risks and mitigation strategies in agriculture is important. Demonstrating successful farm ventures under different risk scenarios would help reduce the fear of insurers. 
Cao Duc Phat also stressed the importance of building effective management capacity for insurance programs and how it needs to be integrated with government policy. He calls for:

To improve the sustainability of public finances, insurance should be combined as a risk management product invested by the private financing agencies with the poverty reduction policies of the Government.

Lele and colleagues question the benefits of index insurance to manage climate risk. It could end up increasing the cost of credit to smallholders, and moral hazard problems exist with respect to the lending institution's incentive for strong loan management practices. The bottom line is:

Whether governments should support index insurance schemes for small holders will be a fiscal policy issue as to whether the subsidy is well targeted and that it is the most efficient use of government resources or the aid provided by a foreign agency or a NGO. There may be other ways to facilitate small holders' risk management and coping strategies more efficiently. Answers will vary from country to country.

\subsection{Cash Transfer Programs}

All of the policy experts note that while the overall concept of using safety nets as one tool to manage climate risk is sound, the effectiveness will be determined by the program design - and here there were several different aspects considered. One important one is that the design of safety net programs to support the management of climate risk needs to be tailored to local conditions. Caron cites results from recent reports of the High Level Panel of Experts (HLPE) of the Committee on Food Security (CFS) that indicated considerable variation in the types of risks, tools and programs and institutional arrangement amongst programs and the importance of considering these conditions in designing effective programs.

Sanchez raises the potential benefits from conditional transfers, where cash payments are based on using the right type and amount of fertilizer or the right variety, or sending your children to school. Cao Duc Phat also noted the importance of accompanying cash transfer programs with technical advice on how best to spend funds, as well as establishing a technical service system to provide agricultural services to meet the needs of farmers (such as seed, chemicals, maintenance, consumer guides and more) to help ensure wise use of the transfers.

Dev cited the asset creation benefits of some of the present social protection programs which are beneficial to the development of climate resilient agriculture. He gives the example of India's public works program MGNREGA. A study by Indian Institute of Science, Bangalore in India quantifies the environmental and socio-economic benefits generated by the works implemented under MGNREGA and assesses the potential of these benefits to reduce vulnerability of agricultural production and livelihoods of the beneficiaries, post-implementation (2011-12) as compared to pre-MGNREGA (2006-07), to current climate variability. Agricultural 
and livelihood vulnerability indices developed showed reduction in vulnerability due to implementation of works under the Act and resulting environmental benefits.

Sibanda points out the importance of understanding which households should receive transfers. She argues that we need to understand the current endowments of the household, including human capacity, education, and health. Do they have a support system that will allow them to utilize cash transfers to engage in Climate Smart Agriculture? What are their natural capital assets such as land and water? Lele et al. agree that there is a strong possibility of using cash transfer programs as a climate management policy but the approach to targeting of this subsidy to eligible beneficiaries could vary from a landscape to landscape.

However Kosura questions the capacity of safety nets to actually mitigate risks, depending on the amount of cash transfer they actually involve. He gives an example from Kenya, where both the Hunger Safety Net Programme (HSNP) and Cash for Asset/Work programs advance households about USD 25 per month. Considering a very poor and vulnerable household with about six family members, the cash advanced will likely not be enough to even meet household food needs.

\subsection{Input Subsidies}

Dev states that subsidies are not sustainable and therefore need to be designed as temporary measures. They also may encourage waste of resources, as is the case in India with water and land. Subsidies lead to inefficient resource allocation by supporting inefficient input sector (e.g. India's domestic fertilizer industry). Furthermore fertilizer subsidies may lead to unsustainable use of land. Some examples of effective subsidies are when they use transfer payments to poor farmers (e.g. a minimum amount of fertilizer for small plots), subsidize valuable technologies when credit markets don't work and the technology generates positive externalities (e.g. drip irrigation).

FISP type programs can have positive impacts by increasing yields and incomes resulting in farmers expanding their financial capital and knowledge base according to Kosura. They can enhance the uptake of valuable technologies, but in the longrun they result in moral hazards, and even corruption, because subsidies become transfer policies and serve to benefit more influential and politically connected farmers. Caron has the same concerns highlighting the role of subsidies in increasing resilience through exposure and learning, but worries about their long-term effect. Sibanda thinks that FISP solves a short-term constraint, but improved productivity in the longer-run requires complementary inputs, like seeds. Given limited budgets, subsidies need to be targeted based on household level vulnerability, need, and productivity gains. It may be worthwhile to consider several types of subsidies, not only fertilizer, but also seeds and the need for establishing effective extension. The big challenge of subsidy program design is overcoming corruption. Therefore adhering to targeting criteria both improves efficiency and improves corruption. 
Sibanda believes that FANRPAN targeting criteria provides a step in the right direction.

Lele et al. state:

Developing countries such as India provide subsidies to farm households indirectly, either through free supply of or reduced prices for inputs such as water, power, seeds, fertilizers and interest- free bank loans. These subsidies tend to benefit wealthier farmers more than poorer farmers who do not necessarily get sufficient access to these inputs either because of the lack of purchasing power or supply constraints. By and large, existing indirect subsidy programs would need to be modified or replaced by new programs that target subsidies mainly to small and marginal farmers adopting new conservation agriculture technologies. It is also important to ensure that the prevailing leakages in subsidy programs are checked by providing cash subsidies against actual purchase of subsidized inputs directly in their bank accounts.

They go on to give examples from India on how this is being accomplished:

In India, the government has advanced considerably in eliminating middlemen in the provision of subsidies directly to farm households, including particularly cash subsidies to small and marginal farmers, by way of direct deposit to eligible farm household's bank accounts. Similar reforms are needed in all types of existing subsidy schemes and redirect the resources so released to support those farmers which shift from conventional to climatesmart conventional agriculture for a limited number of years, i.e., until farmers adopting new technologies are able to restore any productivity or income losses and begin to benefit from using new technologies.

Sanchez acknowledges the problem of corruption, but thinks the benefits of subsidies may outweigh it. He argues that farmers are subsidized in the developed countries, and there should be no reason why they shouldn't be in developing countries. He points out that Malawi subsidy program effectively addressed the food security problem. He argues:

Of course, it didn't alleviate poverty and there is some corruption, but overall it provided more resources and improved the health and capability of the poor. Now that the program reached a certain threshold of performance, it can be modified to address other objectives (for example diversifying diets, increasing resilience, etc).

Phat recognizes the immediate benefit of fertilizers but warn against the tendency of subsidies to lead to distorted market prices and overuse of fertilizer. Indeed in Vietnam farmers have over applied fertilizers and pesticides and the government now informs farmers of recommended dosage and tries to avoid subsidization.

\section{Priorities for the Future and Summary}

In this final section, we asked the policy experts to comment on the case study findings indicating the need for better coherence between climate change, agriculture and development policies and suggest means for achieving this. We also asked them to give us their opinion on the priority actions for near term and provide their direct quotes from their replies. This section concludes with a summary of the main points 
of agreement and divergence amongst our panel in responding to all of the interview questions.

\subsection{Policy Coherence}

Most experts acknowledge the importance of integration and harmonization of climate change consideration into agricultural and non-agricultural sectors to achieve better outcomes. They note that often government ministries work in "silos" and this often works against not only inter-sectoral convergence, but also against intrasectoral convergence. Incentive mechanisms should be put in place to encourage coordination and harmonization among government ministries and also for many actors to adjust behaviors. The need for convergence in climate change activities has to be recognized in policymaking both at center and province levels and in implementation at different levels and building a supportive evidence base as well as explicit recognition of trade-offs and the need for compromises is important to achieving effective coordination.

Dev notes that the silo mentality works against not only inter-sectoral convergence, but also against intra-sectoral convergence. To fully support the agriculture sector requires coordination among the ministries of agriculture, rural development, and commerce, as well as among the various Ministries and Departments relating to food, irrigation, fertilizer and power. He also raises the possibility of inefficiency and disruption arising in trying to build policy coherence, if is it not well done. For example, multiple departments and multiple schemes can cause confusion among staff. The incentive question is important. Officials think they will lose some of their power, if convergence is pursued with other departments and this issue needs to be addressed directly.

Lele and colleagues make many of the same points as Dev, pointing out that for successful implementation of climate change initiatives, it is important to rationalize/harmonize various government regulations, credit policies, subsidy programs and land tenure laws, and get these initiatives effectively integrated into sector planning, budgeting and development. It is also necessary to bring about convergence among different government departments dealing with climate change and their local offices at the landscape level, to be able to effectively implement climate change adaptation planning and implementation using community/participatory methods at least cost. Reducing duplication and redundancy is an important facet here. For example, in India, the existing multi-agency institutional framework involves huge administrative overheads, reduced outlays on real sector development, and much less impact in terms of outputs and outcomes.

The use of evidence based approaches to policy planning and programming and promotion of multi-stakeholder and multi-agency participation in these processes is key for Kosura. The need for institutional capacity to take part in the climate change adaption planning process varies from country to country but generally, there is a need for (i) human capital development through relevant training and skills 
enhancement; (ii) financial capital through targeted resource mobilization for priority projects meant to promote Climate Smart Agriculture for Development; (ii) formulating a clear policy and regulatory framework as well as shaping political will and (iv) regular public-private sector meetings and round table discussions must also be sustained in order to assure political will that is critically essential for success of the policies that require reforms in institutions especially in legislation and resource mobilization strategies.

Sanchez stresses the need for more communications between the climate and agricultural scientists. There are many institutions involved in production and dissemination of information and thus it's imperative to have a policy framework that encourages interactions between the different sectors, Ministries, private companies and farmer associations. There are going to be trade-offs and synergies between promoting productivity and environmental issues and an enabling government environment is needed to handle these in a reasonable way. He notes the importance of education and information to promote this process especially in the developing countries.

Caron starts out by noting that agriculture is at the heart of social transformation and thus a key part of the solution - and not just the problem. He also raises the issue of trade-offs and the need for compromises and thinks these have to be acknowledged to build the conceptual, intellectual and operational framework that puts agriculture as a lever for change in other sectors. He gives the example of the Paris Agreement on Climate, where the word 'agriculture' was not in the final agreement even though the sector plays an essential role in the intended nationally determined contributions (INDCs) to the agreement. He notes that Climate Smart Agriculture is built to address trade-offs between food security, mitigation and adaptation to climate change. Building on this strong conceptual basis looking at the trade-offs, and at the gaps, is a strong avenue towards thinking about agriculture in the future in addressing climate issues.

Cao Duc Phat stress the importance of integration of climate change considerations into sector planning and development. Vietnam is currently conducting agricultural restructuring, in which the long-term plan, strategy, policy, organizational innovation, and improvement of public investment are adjusted and implemented synchronously both inside and outside the sector, at all levels of management, not just some policy changes. He also points out the need to improve and enhance communication and advocating for changing a way of thinking of management people from central to local levels. Forming an evidence-based mechanism and public support should also be integral part of decisions for managing natural resources efficiently. Both require good scientific information and research activities. Lastly, forming the unified coordination system under long-term action plans and effective cross-sectoral and regional coordination mechanism is key for promoting effective integration.

The need to reduce duplication and consider the incentives (and disincentives) for cooperating amongst government agencies is emphasized by Sibanda. She stresses the need for (i) strong leadership that points to the directions that people need to go, and (ii) an analysis that looks at what is needed to be added, and what 
we need to get rid of. She acknowledges that harmonization is not easy and it is important to focus on institutional change that is going to be relevant. Wedding of co-function analysis and co-institutional analysis requires resolute leadership that will pull the trigger where things need to be dropped, and be bold enough to say: 'this we don't know, we need help'. The area of harmonization of policies is a new area and calls for a new way of doing business, which we will need both leadership and mapping to achieve.

\subsection{Policy Priorities for the Next 20 Years}

This section is composed of direct quotes from each of the panel members.

Cao Duc Phat: The priority is to undertake joint scientific research programs to support countries to improve animal and plant breeds, farming systems, technical systems that have better resistance to extreme and unusual climate conditions. This will require support to increasing the effectiveness of South-South cooperation under the 3-sided triangle, in order to transfer experiences, lesson learnt, best technologies and policies among countries with similar conditions or with common problems to be solved. In addition, building operational mechanisms to perform payments for environmental services (for example carbon emissions trading, forest cover, biodiversity levels, etc.) is needed. Strengthening international cooperation in sustainable resource management - especially in the Mekong Delta (e.g. transboundary and multiple country partnership management) supported by transparent information exchange, discussions and cooperation. An important priority for Vietnam is the development of a GHG inventory systems, applying tier 2 and 3 level analysis, for agriculture in order to develop appropriate baselines and carbon footprints - as well as GHG reduction scenarios and development programs that ensure the achievement of development goals, increase productivity, efficient and sustainable uses of natural resources.

Caron: There is an incredible challenge to build intelligence and understanding of the context of where we are. That's even more complicated because we do not know necessarily where we are going. How can we build the capacity, the knowledge, the understanding capacity, the knowledge and the technology that we will be needing in 20 or 30 years' time? There is a need for very strong investment in research that addresses three challenges: better liaison between policy-making and science, secondly to get strong research communities in all parts of the world to address both local and global challenges and third a more global need for investment in research that puts us in a position of preparing what we will need in the future.

Dev: Policy makers, researchers and the international community should recognize that climate change is real and Climate Smart Agriculture should be the present and future priority and work towards achieving climate related adaptation and mitigation measures. Announcement of Sustainable Development Goals (SDGs) 
provides an opportunity for global level cooperation. The Paris CoP21 agreement has to be enforced. There are many promises but not firm commitments.

Kosura: Given the dynamic nature of climate change and diversity of cultural practices and environments, innovative and responsive research to seek for timely solutions should be a priority agenda. Marshaling investment resources for research, infrastructure and information dissemination to avoid possible disasters brought about by climate change is critical. Institutional innovations to minimize institutional failure, moral hazards and corruption should be prioritized. In this way, farmers and stakeholders in general will have the incentives to adopt available technologies to respond to adverse climate change effects.

Lele, Deshpande and Abrol: Our effort should be to work directly with the farmers over a long (10-15 year) time horizon to convince them about the benefits of CA. For this, involvement of social scientists from the very beginning is critical. The Rice Wheat Consortium in the Indo-Gangetic plains, the 'bread bowl' of India and India's neighboring countries was such a program. It was the most successful eco-regional program receiving the King Baudouin Award on behalf of regional NARS. It was closed and the reasons behind its closing are unclear. It reflects the tragedy of international cooperation.

Sanchez: My main focus is on Sub-Sahara Africa. The goal would be in the next 20 years that Africa is producing at a 3 tons per hectare level on maize or equivalent and all this sort of thing. I think very strongly that tackling climate change has to be made into a positive business, where people will make money out of it, either smallholder farmers or big farms. I've been advocating fertilizers a lot: there is a climate price tag to that because manufacturing fertilizers produces methane and negative things on climate. I think it could be lovely if we could do this in a more natural way which is biological nitrogen fixation by legumes. The science is there and it is very positive. However, the adoption has been miserable. Partly, I think, it is because there was no subsidy of any kind. This is the issue that has been mentioned above, i.e. how to enable farmers to get through this two to four-year period in which you're not going to get anything out of it but you're spending money? This has to be arranged, or subsidized or (supported) with long-term credit or whatever. But if we could have more of these nitrogen-fixing trees, they can be used to partially replace nitrogen fertilizers it would be great.

Sibanda: To me the key is the leadership. I think the next 15-30 years require bold leadership and leadership that doesn't lead for today but leads for tomorrow. What that will take is: leadership that has a plan informed by where we are now, where we want to go and how we're going to get there and who is going to get us there. And when I talk about 'who is going to get us there' is the partnership for finance, knowledge and bottom-up policies, i.e. the policy that serves the home ground. 


\subsection{Summary Conclusions}

Overall, there is a fairly high level of agreement amongst the panel members in responding to most of the interview questions, although with some difference in emphasis or applications. However there are also some differences of opinion that emerge from their responses. In the following section, we summarize the main points made on each of the issues addressed, highlighting the areas of agreement, as well as differences.

1. There is a high level of agreement that promoting sustainable land and water management in agriculture, including diversification is a high policy priority, not only for the adaptation benefits they can provide, but also as a key response to improving rural livelihoods under rapidly changing conditions. It was also widely agreed amongst the panel that policy has a fundamental role to play in building the enabling conditions for a major transformation to more sustainable land and water management.

2. The panel indicated that one of the most important policy measures for promoting sustainable and Climate Smart Agriculture is through value chain development - on both the input and output side. Value chains need to be extended and strengthened, but perhaps most importantly repositioned in order to better incorporate both environmental and social externalities. Coordinating collective action through cooperatives, and providing better incentives for sustainable management through improved land and water tenure systems were also considered priority policy actions.

3. Irrigation and improved water management were considered a very high priority for adaptation by the panel, but with much greater emphasis on small scale systems where the users have a high degree of control that can be managed for more than one purpose.

4. There is overall agreement amongst panel members that adaptation to climate change needs to be explicitly integrated into agricultural data and research system, with priorities ranging from building capacity of agricultural technical staff to use climate data to improving systems of communicating and disseminating climate information.

5. Agricultural extension is considered an essential element for Climate Smart Agriculture by the panel - but it needs major rethinking and reform. Building systems that allow for bottom up as well as top down interactions and well as getting correct incentives for extension workers - and building their capacity to use climate data are important.

6. The potential for index insurance as a tool for managing climate risk was generally regarded as positive by the panel but with some skepticism about whether or not it can be scaled up and if it will always need subsidization.

7. The panel considered cash transfer programs as a potentially important tool for managing climate risk for farmers, but its effectiveness depends on good targeting. 
8. Probably the most divergence of views amongst panel members was related to the potential role of input subsidies in Climate Smart Agriculture. On the negative side, they are associated with corruption and inefficiency. On the positive side they have been effective in raising productivity as well as other benefits. Actions to reduce corruption, such as direct deposit payments and improve targeting and eligibility rules can make them more climate smart.

9. There is very strong agreement amongst panel members that greater coherence and integration is needed between agriculture and climate change policies that can lead to reduction in duplication, bureaucracy and costs.

10. Strengthening multi-disciplinary and long term systems research was considered a high priority for several panel members, as was better bridging of the policy-research divide. Developing the political will to actually enforce agreements and fostering institutional innovations to see their effective implementation in the field also emerged as priority actions.

\footnotetext{
Open Access This chapter is distributed under the terms of the Creative Commons AttributionNonCommercial-ShareAlike 3.0 IGO license (https://creativecommons.org/licenses/by-nc-sa/3.0/ igo/), which permits any noncommercial use, duplication, adaptation, distribution, and reproduction in any medium or format, as long as you give appropriate credit to the Food and Agriculture Organization of the United Nations (FAO), provide a link to the Creative Commons license and indicate if changes were made. If you remix, transform, or build upon this book or a part thereof, you must distribute your contributions under the same license as the original. Any dispute related to the use of the works of the FAO that cannot be settled amicably shall be submitted to arbitration pursuant to the UNCITRAL rules. The use of the FAO's name for any purpose other than for attribution, and the use of the FAO's logo, shall be subject to a separate written license agreement between the FAO and the user and is not authorized as part of this CC-IGO license. Note that the link provided above includes additional terms and conditions of the license.

The images or other third party material in this chapter are included in the chapter's Creative Commons license, unless indicated otherwise in a credit line to the material. If material is not included in the chapter's Creative Commons license and your intended use is not permitted by statutory regulation or exceeds the permitted use, you will need to obtain permission directly from the copyright holder.
} 